\title{
Synthesis and Characterization of K-Ta Mixed Oxides for Hydrogen Generation in Photocatalysis
}

\author{
Beata Zielińska, Ewa Mijowska, and Ryszard J. Kalenczuk \\ Institute of Chemical and Environment Engineering, West Pomeranian University of Technology, Szczecin, Pułaskiego 10, \\ 70-322 Szczecin, Poland \\ Correspondence should be addressed to Beata Zielińska, bzielinska@zut.edu.pl
}

Received 27 February 2012; Accepted 16 April 2012

Academic Editor: Ignazio Bellobono

Copyright ( 2012 Beata Zielińska et al. This is an open access article distributed under the Creative Commons Attribution License, which permits unrestricted use, distribution, and reproduction in any medium, provided the original work is properly cited.

K-Ta mixed oxides photocatalysts have been prepared by impregnation followed by calcination. The influence of the reaction temperature $\left(450^{\circ} \mathrm{C}-900^{\circ} \mathrm{C}\right)$ on the phase formation, crystal morphology, and photocatalytic activity in hydrogen generation of the produced materials was investigated. The detailed analysis has revealed that all products exhibit high crystallinity and irregular structure. Moreover, two different crystal structures of potassium tantalates such as $\mathrm{KTaO}_{3}$ and $\mathrm{K}_{2} \mathrm{Ta}_{4} \mathrm{O}_{11}$ were obtained. It was also found that the sample composed of $\mathrm{KTaO}_{3}$ and traces of unreacted $\mathrm{Ta}_{2} \mathrm{O}_{5}$ (annealed at $600^{\circ} \mathrm{C}$ ) exhibits the highest activity in the reaction of photocatalytic hydrogen generation. The crystallographic phases, optical and vibronic properties were examined by $\mathrm{X}$ ray diffraction (XRD) and diffuse reflectance (DR) UV-vis and resonance Raman spectroscopic methods, respectively. Morphology and chemical composition of the produced samples were studied using a high-resolution transmission electron microscope (HRTEM) and an energy dispersive X-ray spectrometer (EDX) as its mode.

\section{Introduction}

Photocatalytic water splitting into hydrogen and oxygen has been extensively studied since 1971, when Honda and Fujishima observed effect of water splitting using a $\mathrm{TiO}_{2}$ electrode. Now, over 130 materials are known as active photocatalysts for water splitting $[1,2]$. A large group of photocatalysts tested in the reaction of hydrogen generation are based on various tantalates. For example, Kato and Kudo stated in 1998 that tantalates $\mathrm{MTaO}_{3}(\mathrm{M}=\mathrm{Li}, \mathrm{Na}, \mathrm{K})$ with a perovskite structure produced via solid-state reaction at the temperature of $1420 \mathrm{~K}$ are effective photocatalysts for water splitting under UV irradiation [3]. Since then, many tantalates such as $\mathrm{M}_{2} \mathrm{Ta}_{2} \mathrm{O}_{6}(\mathrm{M}=\mathrm{Na}, \mathrm{K})$ [4], $\mathrm{MTa}_{2} \mathrm{O}_{6}$ $(\mathrm{M}=\mathrm{Ca}, \mathrm{Sr}, \mathrm{Ba})$ [5], $\mathrm{Rb}_{4} \mathrm{Ta}_{6} \mathrm{O}_{17}$ [6], $\mathrm{M}_{5} \mathrm{Ta}_{4} \mathrm{O}_{15}(\mathrm{M}=$ $\mathrm{Sr}, \mathrm{Ba})[7,8]$, and $\mathrm{K}_{3} \mathrm{Ta}_{3} \mathrm{~B}_{2} \mathrm{O}_{12}$ [9] have been found as high active photocatalysts for hydrogen generation. The high photocatalytic activity of tantalates was attributed to the suitable conduction band level consisting of Ta5d and the efficient carrier delocalization caused by the proper distortion of $\mathrm{TaO}_{6}$ connections $[1,2,10]$.
Among various potassium tantalates, metatantalate $\mathrm{KTaO}_{3}$ with perovskite structure has focused research interest due to its outstanding dielectric, photoconductive and nonlinear performance at low temperature. Therefore it is a great candidate for such applications as electric capacitors, luminescence capacitor, fuel cells, microwave tunable devices, and photocatalyst [11]. The activity of pristine and doped $\mathrm{KTaO}_{3}$ in the reaction of photocatalytic decomposition of water was studied [12]. Here, the authors stated that $\mathrm{NiO} / \mathrm{KTaO}_{3}$ doped with $8 \mathrm{~mol} \% \mathrm{Zr}^{4+}$ exhibited higher activity in the photocatalytic decomposition of water than that of well-known photocatalyst- $\mathrm{Pt} / \mathrm{TiO}_{2}$. Ishihara et al. [13] studied photocatalytic hydrogen evolution over K-Ta mixed oxides with two different crystal structures, that is, $\mathrm{KTaO}_{3}$ and $\mathrm{K}_{2} \mathrm{Ta}_{2} \mathrm{O}_{6}$. The authors indicated that $\mathrm{K}_{2} \mathrm{Ta}_{2} \mathrm{O}_{6}$ exhibited the higher activity in photolytic splitting of $\mathrm{H}_{2} \mathrm{O}$ than that of $\mathrm{KTaO}_{3}$. They argued that higher formation rate of $\mathrm{H}_{2}$ on $\mathrm{K}_{2} \mathrm{Ta}_{2} \mathrm{O}_{6}$ could be explained by the larger surface area, smaller crystalline size, and different crystal structure. Ikeda et al. [4] studied photocatalytic water splitting in the presence of tantalate and niobate pyrochlores, $\mathrm{Ca}_{2} \mathrm{M}_{2} \mathrm{O}_{7}$ 
$(\mathrm{M}=\mathrm{Nb}, \mathrm{Ta})$ and $\mathrm{A}_{2} \mathrm{Ta}_{2} \mathrm{O}_{6}(\mathrm{~A}=\mathrm{Na}, \mathrm{K})$. They stated that $\mathrm{NiO} / \mathrm{K}_{2} \mathrm{Ta}_{2} \mathrm{O}_{6}$ showed the highest photocatalytic activity among all studied materials.

In this contribution, the procedure of (impregnation followed by calcination) was applied to prepare K-Ta mixed oxides photocatalysts. The influence of the calcination temperature of the sample in the range of $450^{\circ} \mathrm{C}-900^{\circ} \mathrm{C}$ on the phase formation, crystal morphology, and photocatalytic activity in hydrogen generation will be presented.

\section{Experimental}

High-purity grade tantalum pentoxide $\left(\mathrm{Ta}_{2} \mathrm{O}_{5}\right.$, purity 99.99\%, Sigma-Aldrich) and potassium hydroxide $(\mathrm{KOH}$, purity $98 \%$, Sigma-Aldrich) were used as precursors for the preparation of K-Ta mixed oxides photocatalysts. Here, the two-step synthesis (impregnation and calcination) was used. The molar ratio of $\mathrm{KOH}: \mathrm{Ta}_{2} \mathrm{O}_{5}$ was $2: 1$. In the preparation procedure, the excess amount of potassium hydroxide (10\%) was added to compensate the volatilization. The excess of $\mathrm{KOH}$ was washed out with water. In the first step $\mathrm{Ta}_{2} \mathrm{O}_{5}$ was impregnated in an aqueous solution of $\mathrm{KOH}$. Afterwards, the as-obtained material was dried at temperature of $70^{\circ} \mathrm{C}$ for $24 \mathrm{~h}$. Next, the dried material was divided into ten equal batches which were calcinated in the temperature range between $450^{\circ} \mathrm{C}$ and $900^{\circ} \mathrm{C}$ with the step of $50^{\circ} \mathrm{C}$. The annealing time at required temperature was fixed to 11 hours. The annealed samples are labeled as $K-T$ (T means the temperature of calcination).

The phase composition of the samples was characterized by X-ray diffraction (XRD) analysis (X'Pert PRO Philips diffractometer) using a $\mathrm{CuK}_{\alpha}$ radiation. The morphology and chemical composition of the produced samples were examined using a high-resolution transmission electron microscopy (HR-TEM-FEI Tecnai F30) and energy dispersive Xray spectrometer (EDX) as its mode. The resonance Raman study was performed using Resonance Raman Renishaw InVia Microscope with laser length $785 \mathrm{~nm}$. The optical properties of the catalysts were studied via diffuse reflectance (DR) UV-vis technique using Jasco (Japan) spectrophotometer. Finally, the specific surface areas and the mean pore diameters of catalysts were measured by nitrogen gas adsorption method using Micrometrics ASAP 2010 device.

The photocatalytic hydrogen evolution reactions were carried out in a closed system with inner-irradiation-type reactor. The light source was a medium pressure mercury lamp of $150 \mathrm{~W}$. The light of wavelength ranging from $200 \mathrm{~nm}$ to $600 \mathrm{~nm}$ with the maximum intensity of $366 \mathrm{~nm}$ was emitted. The $\mathrm{H}_{2}$ evolution reactions were performed with formic acid solution $\left(0.1 \mathrm{~mol} / \mathrm{dm}^{3}\right)$ and constant amount of $K-T$ catalysts $(0.2 \mathrm{~g})$. Firstly, powder of the photocatalysts was dispersed in $800 \mathrm{~cm}^{3}$ of aqueous solution of formic acid. Afterwards, the suspension was mixed with a magnetic stirrer for 1 hour in the presence of argon flow to remove oxygen. Finally, the solution was irradiated for 2 hours without argon purging. The evolved hydrogen was determined using a gas chromatograph (Chrome 5) equipped with a thermal conductivity detector (TCD).

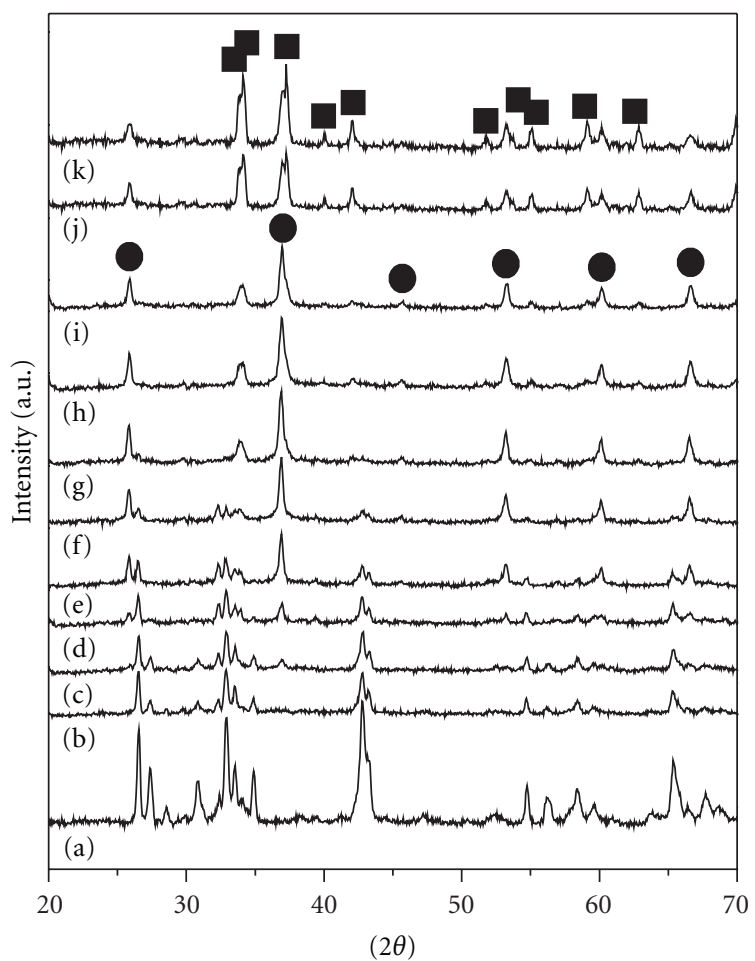

Figure 1: XRD patterns of $\mathrm{Ta}_{2} \mathrm{O}_{5}$ (a), K-450 (b), K-500 (c), K-550 (d), K-600 (e), K-650 (f), K-700 (g), K-750 (h), K-800 (i), K-850 (j), $\mathrm{K}-900(\mathrm{k})\left(-\mathrm{KTaO}_{3}, \boldsymbol{\square}-\mathrm{K}_{2} \mathrm{Ta}_{4} \mathrm{O}_{11}\right)$.

\section{Results and Discussion}

The crystallographic composition of the $K-T$ samples was studied via XRD. Figure 1 shows the XRD patterns of starting $\mathrm{Ta}_{2} \mathrm{O}_{5}$ (pattern a) and the materials produced after calcination of $\mathrm{Ta}_{2} \mathrm{O}_{5}$ and potassium hydroxide in different temperatures ((b) K-450, (c) K-500, (d) K-550, (e) K600, (f) K-650, (g) K-700, (h) K-750, (i) K-800, (j) K850 , (k) K-900). XRD of the sample annealed at $450^{\circ} \mathrm{C}$ shows only the diffraction peaks of $\mathrm{Ta}_{2} \mathrm{O}_{5}$. It indicates that these thermal conditions did not induce the formation of potassium tantalates phases with potassium hydroxide as $\mathrm{K}$ precursor. The increase of the calcination temperature to $500^{\circ} \mathrm{C}$ led to the appearance of the diffraction peaks of potassium tantalate with a cubic perovskite structure $\left(\mathrm{KTaO}_{3}, \mathrm{JCPDS}\right.$ card no. 77-0918). However, this sample $(K-500)$ is a mixture of $\mathrm{KTaO}_{3}$ and tantalum pentoxide $\left(\mathrm{Ta}_{2} \mathrm{O}_{5}\right)$. The samples annealed at higher temperature up to $650^{\circ} \mathrm{C}$ reveal the presence of the same two phases, but the relative intensity of the corresponding peaks is changed. When thecalcination temperature increases to $700^{\circ} \mathrm{C}(\mathrm{K}$ $700)$, the peaks corresponding to the additional phase $\left(\mathrm{K}_{2} \mathrm{Ta}_{4} \mathrm{O}_{11}\right.$ (JCPDS card no. 12-0092)) appeared and the $\mathrm{K}$ 700 is a mixture of three phases such as $\mathrm{KTaO}_{3}$ (main phase), $\mathrm{K}_{2} \mathrm{Ta}_{4} \mathrm{O}_{11}$, and $\mathrm{Ta}_{2} \mathrm{O}_{5}$. The samples prepared at $750^{\circ} \mathrm{C}-900^{\circ} \mathrm{C}$ (K-750, K-800, K-850, K-900) contain only two different forms of potassium tantalate: $\mathrm{KTaO}_{3}$ and $\mathrm{K}_{2} \mathrm{Ta}_{4} \mathrm{O}_{11}$. When the calcination temperature increases from $700^{\circ} \mathrm{C}$ to $900^{\circ} \mathrm{C}$, the intensity of the peaks attributed to $\mathrm{K}_{2} \mathrm{Ta}_{4} \mathrm{O}_{11}$ increases. 
Therefore, it is assumed that formation of $\mathrm{K}_{2} \mathrm{Ta}_{4} \mathrm{O}_{11}$ is due to the loss of potassium being evaporated during hightemperature calcination.

The morphology and chemical composition of the samples were studied using HR-TEM and EDX as its mode. The TEM images and EDX spectra of the pristine $\mathrm{Ta}_{2} \mathrm{O}_{5}$ and five representative samples $K-500, K-600, K-700, K-800$, and $K-900$ are presented in Figure 2. All studied samples exhibit high crystallinity. Moreover, irregular structures of the produced samples have been observed. Here, K-500 (Figure 2(b)) is the mixture of two different phases. Probably new phase $\left(\mathrm{KTaO}_{3}\right)$ is embedded in $\mathrm{Ta}_{2} \mathrm{O}_{5}$. Moreover, systematic microscopic analysis of the samples revealed that the particles size increased upon the increase of the annealing temperature. Additionally, EDX spectrum shows that the copper (from the TEM grid), carbon (amorphous carbon growing during TEM investigation), tantalum, and oxygen are only elements present in $\mathrm{Ta}_{2} \mathrm{O}_{5}$. In the annealed samples potassium is also detected, and its content increases along with increase of the calcination temperature. This is in agreement with XRD data of the samples.

To estimate the band gap energy of the samples containing new phases $\left(\mathrm{KTaO}_{3}\right.$ and $\left.\mathrm{K}_{2} \mathrm{Ta}_{4} \mathrm{O}_{11}\right)$ the optical analysis was conducted. The DR-UV/vis absorption spectra of $K-T$ powders are shown in Figure 3. As shown in Figure 3 the absorption edge of $K-T$ samples is shifted toward the longer wavelength with the increase of the calcination temperature. It indicates that the red shift of the band gap energy occurred. To determine the band gap energy of all investigated samples, the Kubelka-Munk method based on the DR-UV-vis spectra was employed. Greater details of the band gap energy calculations have been provided elsewhere [14]. The dependence of the calcination temperature on the value of band gaps of $K-T$ samples is presented in Figure 4 . The inset of Figure 4 illustrates the plot of $(\mathrm{F}(\mathrm{R}) \mathrm{h})^{1 / 2}$ versus photon energy (hv) for $K-500$. The calculated band gap energies of $K-500, K-550, K-600, K-650, K-700, K-750, K-800$, $K-850, K-900$ are $3.69 \mathrm{eV}, 3.57 \mathrm{eV}, 3.40 \mathrm{eV}, 3.36 \mathrm{eV}, 3.32 \mathrm{eV}$, $3.30 \mathrm{eV}, 3.23 \mathrm{eV} 3.2 \mathrm{eV}$, and $3.18 \mathrm{eV}$, respectively. This can be also explained by the formation of new crystal phase.

Next, the samples were investigated by means of Raman spectroscopy (Figure 5). Figure 5(a) shows that Raman of the pristine $\mathrm{Ta}_{2} \mathrm{O}_{5}$ (a) and $K-T$ (b-e) corresponds to Raman response of the samples annealed between $500^{\circ} \mathrm{C}$ and $650^{\circ} \mathrm{C}$. Raman spectra of $K-T$ catalysts calcinated in temperature between $700^{\circ} \mathrm{C}$ and $900^{\circ} \mathrm{C}$ are presented in Figure 5(b). It has been reported $[15,16]$ that low-frequency Raman bands $\left(100-450 \mathrm{~cm}^{-1}\right.$ ) presented in $\mathrm{Ta}_{2} \mathrm{O}_{5}$ spectrum (Figure 5(a)) are assigned to $\mathrm{O}-\mathrm{Ta}-\mathrm{O}$ bending vibrations, whereas the high frequency bands $\left(450-900 \mathrm{~cm}^{-1}\right)$ are characteristic for the stretching modes of various $\mathrm{Ta}-\mathrm{O}$ bands with different bonding strengths. From Figures 5(a) and 5(b) it is clearly seen that Raman spectra of $K-T$ samples differ significantly in respect to the pristine $\mathrm{Ta}_{2} \mathrm{O}_{5}$. According to the XRD analysis, the K-500, K-550, K-600 and K-650 samples are composed of the mixture of $\mathrm{KTaO}_{3}$ and unreacted $\mathrm{Ta}_{2} \mathrm{O}_{5}$. The clear peaks characteristic of $\mathrm{Ta}_{2} \mathrm{O}_{5}\left(\sim 253 \mathrm{~cm}^{-1}\right.$ and $\left.\sim 711 \mathrm{~cm}^{-1}\right)$ can be observed for the samples produced in the temperature ranges from $500^{\circ} \mathrm{C}$ to $600^{\circ} \mathrm{C}(\mathrm{K}-500, \mathrm{~K}-550$, and $\mathrm{K}-600)$.
Moreover, new broad peaks at about 126, 460, $834 \mathrm{~cm}^{-1}$ and in the region of $190 \mathrm{~cm}^{-1}-306 \mathrm{~cm}^{-1}$ and $500 \mathrm{~cm}^{-1}-746 \mathrm{~cm}^{-1}$ are detected in the samples annealed in the tempeature range from $500^{\circ} \mathrm{C}$ to $600^{\circ} \mathrm{C}$. It proves new phase $\left(\mathrm{KTaO}_{3}\right)$ formation. For S-650 the new clear Raman bands at 126, $159,214,282,460,588,750$, and $828 \mathrm{~cm}^{-1}$ are observed. All those peaks are characteristic of $\mathrm{KTaO}_{3}[17,18]$. Moreover, for K-650 the Raman peaks at $\sim 253 \mathrm{~cm}^{-1}$ and $\sim 711 \mathrm{~cm}^{-1}$ assigned to $\mathrm{Ta}_{2} \mathrm{O}_{5}$ are not detected which means that their concentration is beyond the detection limit of Raman spectroscopy. Figure 5(b) indicates the presence of additional Raman peaks in the samples obtained from $700^{\circ} \mathrm{C}$ to $900^{\circ} \mathrm{C}$. It indicates that the additional phase was formed. Therefore, a clear agreement with XRD data is also demonstrated.

The phase composition, BET surface areas, and the mean pore diameters of the studied samples are listed in Table 1. According to the data of manufacture, $\mathrm{Ta}_{2} \mathrm{O}_{5}$ has a small BET surface area of $1.34 \mathrm{~m}^{2} / \mathrm{g}$ and a mean pore diameter of about $10.08 \mathrm{~nm}$. One could observe that all $K-T$ catalysts exhibit higher BET surface areas than that of $\mathrm{Ta}_{2} \mathrm{O}_{5}$. For example, the BET surface area of $\mathrm{K}-500$ is higher by the factor of five in respect to the pristine $\mathrm{Ta}_{2} \mathrm{O}_{5}$. Moreover, in Table 1 it is shown that BET surface area of the samples decreases with the increase of the calcination temperature from $500^{\circ} \mathrm{C}$ to $900^{\circ} \mathrm{C}$.

To determine the photocatalytic activity of the synthesized $K-T$ catalysts, the hydrogen evolution was investigated. The photocatalytic activity of the samples was studied only for the samples containing potassium tantalates as a main phase: K-600, K-650, K-700, K-750, K-800, K850 , and $K-900$. The results of hydrogen generation are shown in Figure 6. The kinetics of hydrogen generation in the presence of formic acid during the first 2 hours of UV irradiation can be described by zero order kinetics. The dependence of the calcination temperature on the $\mathrm{H}_{2}$ evolution rate is shown in Figure 7. Here, one can notice that the photocatalytic activity of the produced catalysts is strongly influenced by the annealing temperature. The amount of the released hydrogen decreases when the calcination temperature was between $600^{\circ} \mathrm{C}(2.56 \mu \mathrm{mol} / \mathrm{min})$ and $900^{\circ} \mathrm{C}(1.09 \mu \mathrm{mol} / \mathrm{min})$. Additionally, the clear decrease of $\mathrm{H}_{2}$ evolution (from $2.39 \mu \mathrm{mol} / \mathrm{min}$ to $1.37 \mu \mathrm{mol} / \mathrm{min}$ ) was observed for the catalysts calcinated at the temperature above $700^{\circ} \mathrm{C}$ (see Figure 7). Based on XRD analysis it was shown that these catalysts $(K-750, K-800, K-850, K-900)$ are composed of two tantalate phases such as $\mathrm{KTaO}_{3}$ and $\mathrm{K}_{2} \mathrm{Ta}_{4} \mathrm{O}_{11}$. It is interesting that decrease of hydrogen generation was obtained when the samples contained $\mathrm{K}_{2} \mathrm{Ta}_{4} \mathrm{O}_{11}$ as a second tantalate phase. It seems that $\mathrm{K}_{2} \mathrm{Ta}_{4} \mathrm{O}_{11}$ limits the effect of $\mathrm{H}_{2}$ evolution. It is known that the photocatalytic activity of the catalysts is dominated by several parameters for example, the crystal structures, crystalline size, phase composition, electronic structures, and surface area. For example, the smaller crystallites are more active due to larger surface area [12]. Moreover, the larger crystallites are not desired for the photocatalysts, because the diffusion length of the excited electron and hole to the active sites becomes longer, and probability of hole and electron recombination increases [13]. The crystallinity of the catalysts is also an 

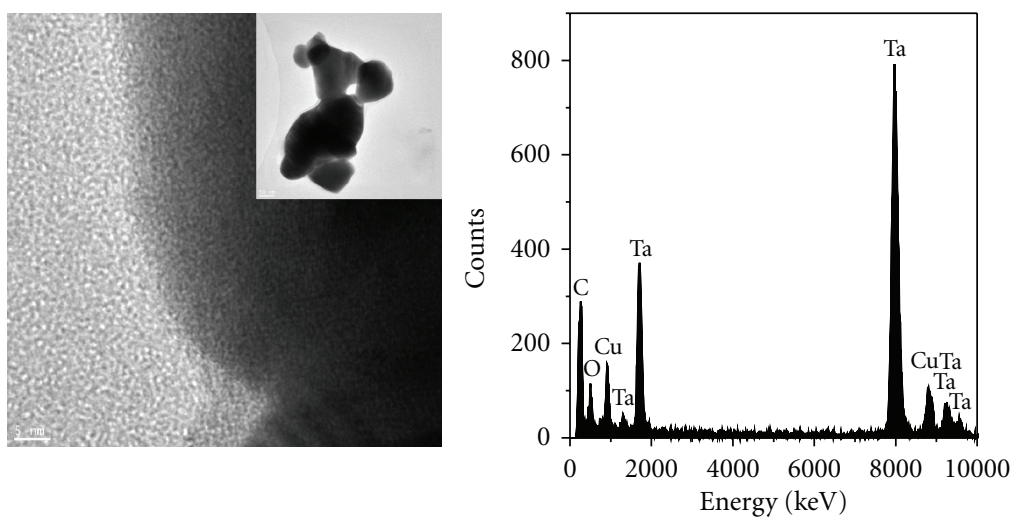

(a)
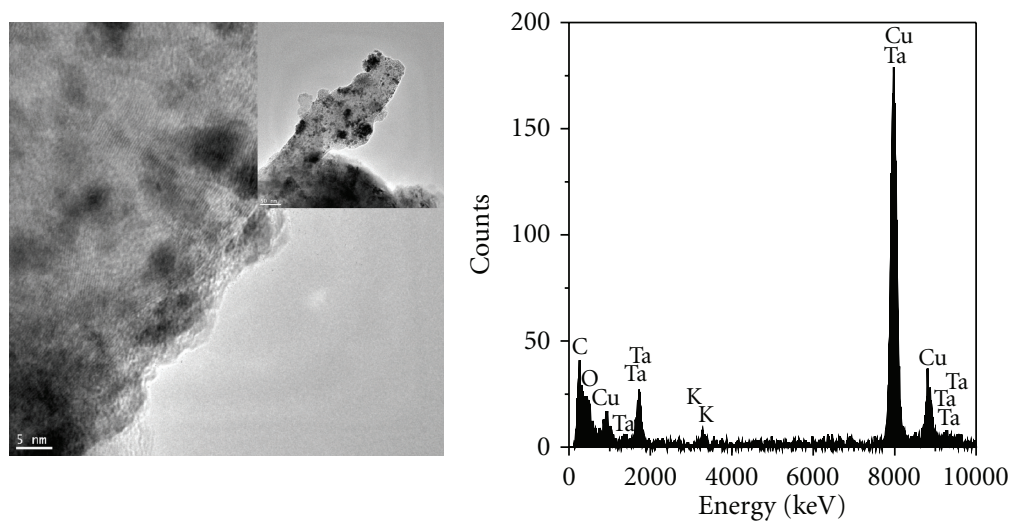

(b)
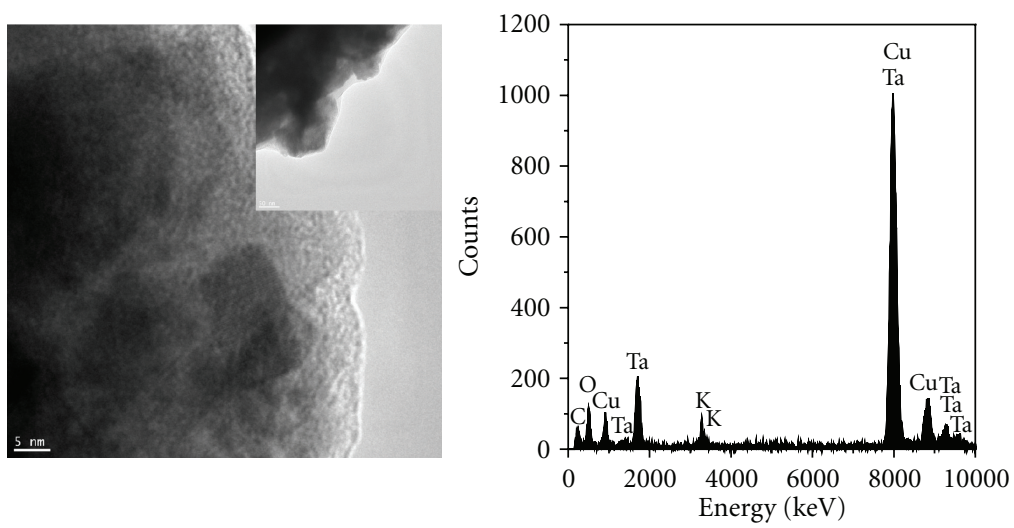

(c)
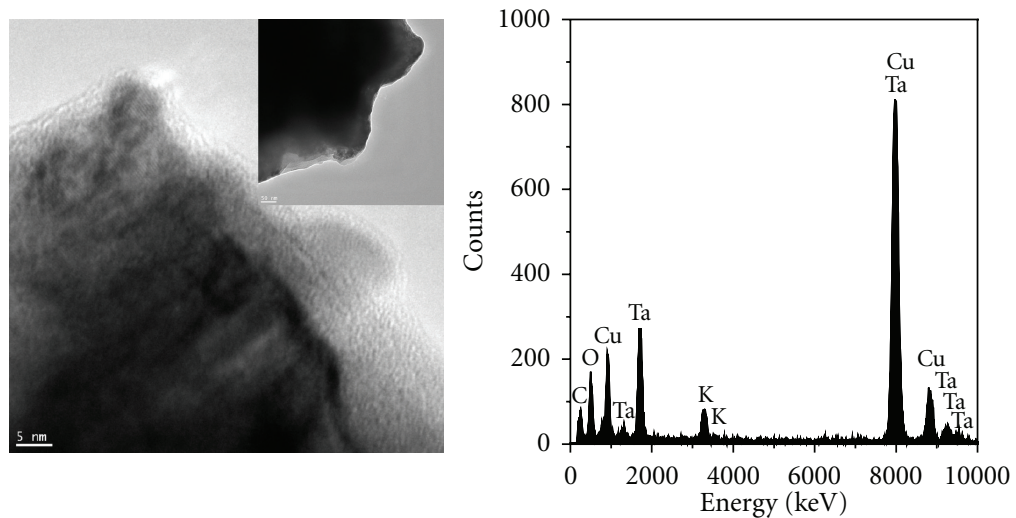

(d)

Figure 2: Continued. 

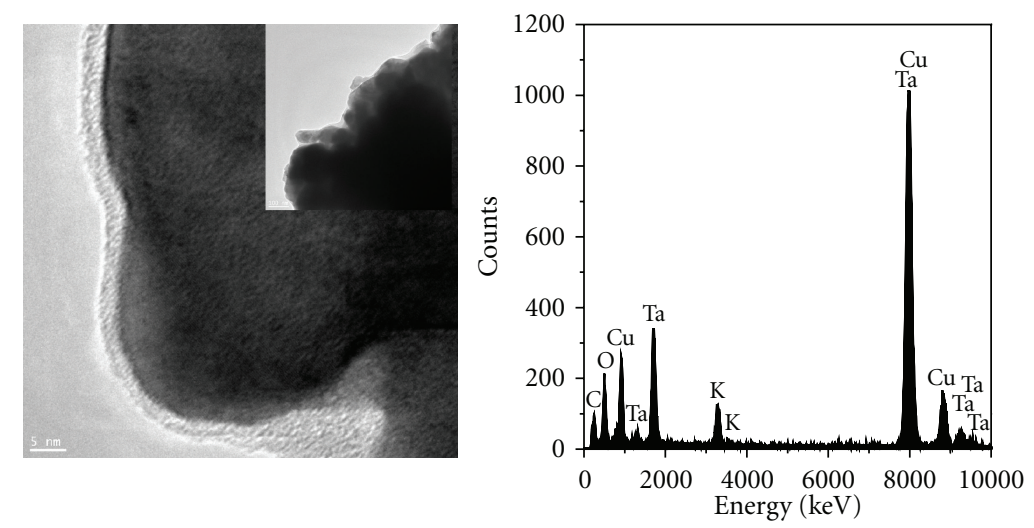

(e)
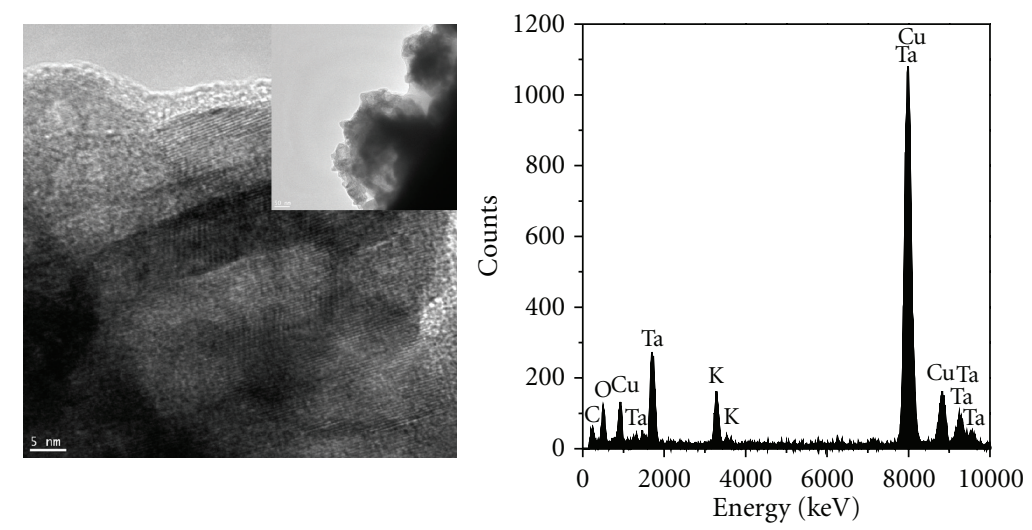

(f)

Figure 2: TEM images and EDX spectra of samples: (a) K-500, (b) K-600, (c) K-700, (d) K-800, and (e) K-900.

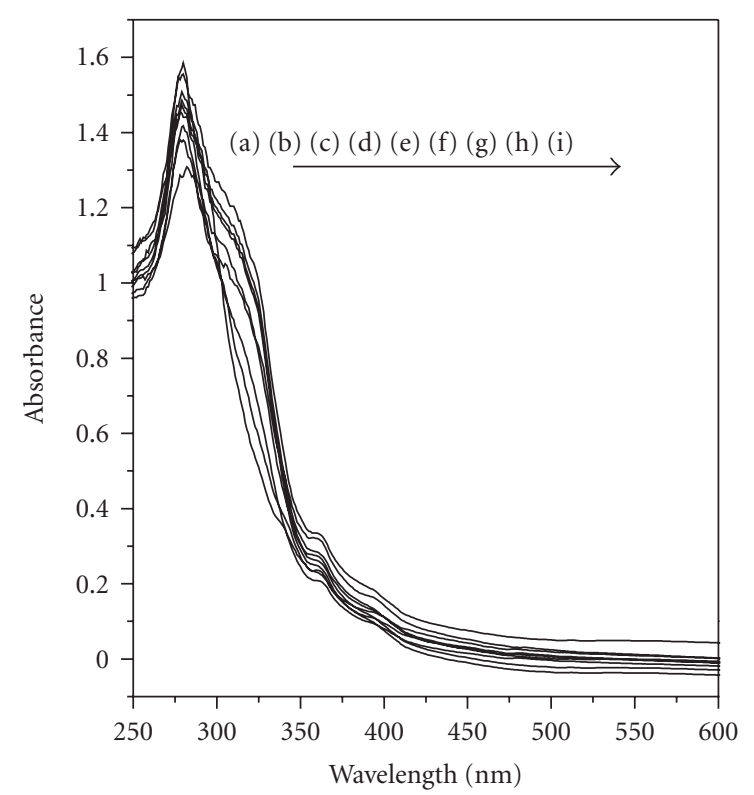

Figure 3: UV-vis spectra of samples: (a) K-500, (b) K-550, (c) K600, (d) K-650, (e) K-700, (f) K-750, (g) K-800, (h) K-850, and (i) K-900.

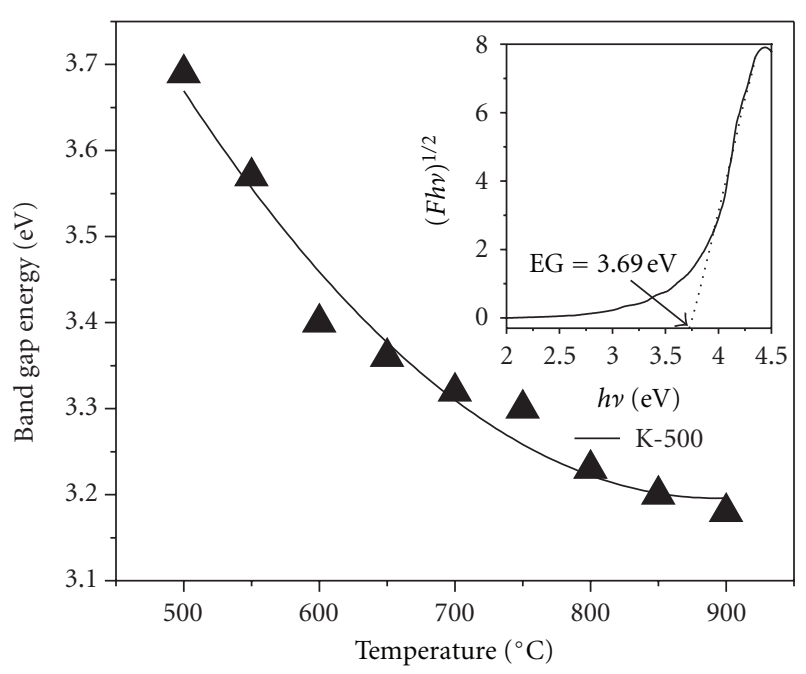

Figure 4: The dependence of the calcination temperature on the values of band gap energy of produced catalysts (the insetKubelka-Munk plot for band gap evaluation of K-500 sample). 


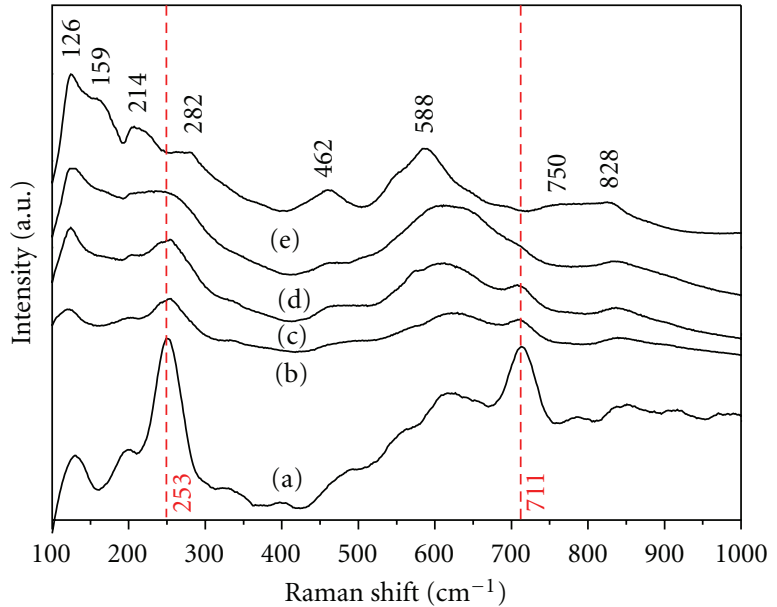

(a)

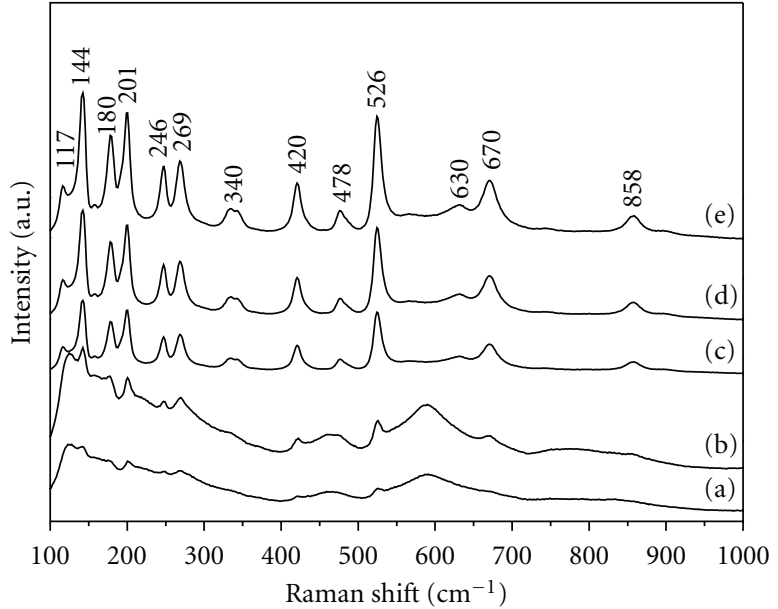

(b)

Figure 5: (a) Raman spectra of samples: (a) $\mathrm{Ta}_{2} \mathrm{O}_{5}$, (b) K-500, (c) K-550, (d) K-600 and (e) K-650. (b) Raman spectra of samples: (a) K-700, (b) K-750, (c) K-800, (c) K-850 and (e) K-900.

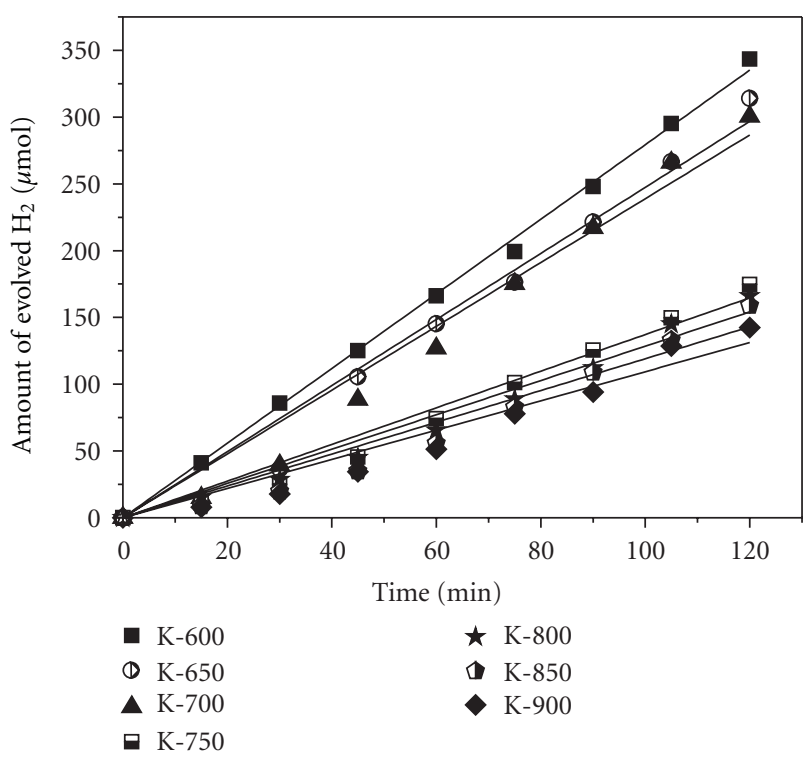

Figure 6: Photocatalytic $\mathrm{H}_{2}$ evolution over $K-T$ catalysts ( $\mathrm{HCOOH}$ concentration $-0.1 \mathrm{~mol} / \mathrm{dm}^{3}$, amount of catalyst $-0.2 \mathrm{~g}$ ).

important parameter. This strongly affects the migration of photoexcited carriers. The higher the crystallinity, the fewer the number of defects is observed (recombination centers between photoexcited electrons and holes). It can result in an increase of the photocatalytic activity [19]. Here, the decrease of the released $\mathrm{H}_{2}$ with decreasing surface area (see Table 1) and increasing particle size (see Figure 2 ) is observed. It was also found that the sample obtained at $600^{\circ} \mathrm{C}(K-600)$ and composed of two crystal phase, such as $\mathrm{KTaO}_{3}$ and traces of unreacted $\mathrm{Ta}_{2} \mathrm{O}_{5}$, exhibits the highest photocatalytic activity for $\mathrm{H}_{2}$ generation. This can be explained by the highest surface area $\left(\sim 5 \mathrm{~m}^{2} / \mathrm{g}\right)$ and the optimal phase composition

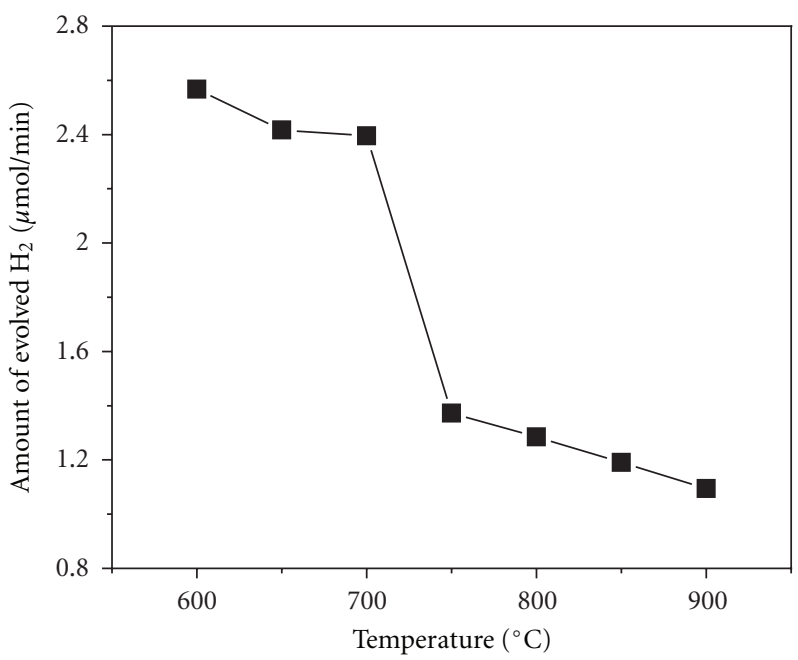

FIgURE 7: The dependence of the calcination temperature on the amount of evolved hydrogen $(\mathrm{HCOOH}$ concentration $-0.1 \mathrm{~mol} /$ $\mathrm{dm}^{3}$, amount of catalyst $-0.2 \mathrm{~g}$ ).

of this sample. Both factors seem to be crucial in the yield of the studied photocatalytic process.

\section{Conclusion}

In summary, potassium tantalate photocatalysts were synthesized by impregnation followed by calcination and then used for $\mathrm{H}_{2}$ production from formic acid solution via photocatalytic process. The following conclusions are provided: (i) all produced catalysts exhibit high crystallinity and irregular structure, (ii) two different crystal structures of potassium tantalates, that is, $\mathrm{KTaO}_{3}$ and $\mathrm{K}_{2} \mathrm{Ta}_{4} \mathrm{O}_{11}$ were, 
TABLE 1: Properties of unreacted $\mathrm{Ta}_{2} \mathrm{O}_{5}$ and $K-T$ samples.

\begin{tabular}{lccc}
\hline Sample & $\begin{array}{c}\text { Phase composition of } \\
\text { synthesized sample }\end{array}$ & $\begin{array}{c}\text { BET surface } \\
\text { area }\left(\mathrm{m}^{2} / \mathrm{g}\right)\end{array}$ & $\begin{array}{c}\text { Mean pore } \\
\text { diameter } \\
(\mathrm{nm})\end{array}$ \\
\hline $\mathrm{Ta}_{2} \mathrm{O}_{5}$ & $\mathrm{Ta}_{2} \mathrm{O}_{5}$ & 1.34 & 10.08 \\
$\mathrm{~K}-500$ & $\mathrm{Ta}_{2} \mathrm{O}_{5} / \mathrm{KTaO}_{3}$ & 7.13 & 5.37 \\
$\mathrm{~K}-550$ & $\mathrm{Ta}_{2} \mathrm{O}_{5} / \mathrm{KTaO}_{3}$ & 6.46 & 6.12 \\
$\mathrm{~K}-600$ & $\mathrm{Ta}_{2} \mathrm{O}_{5} / \mathrm{KTaO}_{3}$ & 4.99 & 7.67 \\
$\mathrm{~K}-650$ & $\mathrm{Ta}_{2} \mathrm{O}_{5} / \mathrm{KTaO}_{3}$ & 3.82 & 8.88 \\
$\mathrm{~K}-700$ & $\mathrm{Ta}_{2} \mathrm{O}_{5} / \mathrm{KTaO}_{3} / \mathrm{K}_{2} \mathrm{Ta}_{4} \mathrm{O}_{11}$ & 3.50 & 8.66 \\
$\mathrm{~K}-750$ & $\mathrm{KTaO}_{3} / \mathrm{K}_{2} \mathrm{Ta}_{4} \mathrm{O}_{11}$ & 3.13 & 8.48 \\
$\mathrm{~K}-800$ & $\mathrm{KTaO}_{3} / \mathrm{K}_{2} \mathrm{Ta}_{4} \mathrm{O}_{11}$ & 2.95 & 9.32 \\
$\mathrm{~K}-850$ & $\mathrm{KTaO}_{3} / \mathrm{K}_{2} \mathrm{Ta}_{4} \mathrm{O}_{11}$ & 2.66 & 9.56 \\
$\mathrm{~K}-900$ & $\mathrm{KTaO}_{3} / \mathrm{K}_{2} \mathrm{Ta}_{4} \mathrm{O}_{11}$ & 2.31 & 9.76 \\
\hline
\end{tabular}

obtained, (iii) the surface area of investigated samples decreased when the calcination temperature increased, (iiii) the sample exhibiting the highest activity in photocatalytic hydrogen generation in the presence of formic acid is composed of $\mathrm{KTaO}_{3}$, and traces of unreacted $\mathrm{Ta}_{2} \mathrm{O}_{5}(K-600)$. $K-600$ exhibit the highest surface area $\left(\sim 5 \mathrm{~m}^{2} / \mathrm{g}\right)$ among all investigated samples.

\section{References}

[1] F. E. Osterloh, "Inorganic materials as catalysts for photochemical splitting of water," Chemistry of Materials, vol. 20, no. 1, pp. 35-54, 2008.

[2] A. Kudo and Y. Miseki, "Heterogeneous photocatalyst materials for water splitting," Chemical Society Reviews, vol. 38, no. 1, pp. 253-278, 2009.

[3] H. Kato and A. Kudo, "New tantalate photocatalysts for water decomposition into $\mathrm{H}_{2}$ and $\mathrm{O}_{2}$," Chemical Physics Letters, vol. 295, no. 5-6, pp. 487-492, 1998.

[4] S. Ikeda, M. Fubuki, Y. K. Takahara, and M. Matsumura, "Photocatalytic activity of hydrothermally synthesized tantalate pyrochlores for overall water splitting," Applied Catalysis A, vol. 300, no. 2, pp. 186-190, 2006.

[5] H. Kato and A. Kudo, "Photocatalytic decomposition of pure water into $\mathrm{H}_{2}$ and $\mathrm{O}_{2}$ over $\mathrm{SrTa}_{2} \mathrm{O}_{6}$ prepared by a flux method," Chemistry Letters, vol. 28, no. 11, pp. 1207-1208, 1999.

[6] K. Sayama, H. Arakawa, and K. Domen, "Photocatalytic water splitting on nickel intercalated $\mathrm{A}_{4} \mathrm{Ta}_{x} \mathrm{Nb}_{6-x} \mathrm{O}_{17}(\mathrm{~A}=\mathrm{K}, \mathrm{Rb})$," Catalysis Today, vol. 28, no. 1-2, pp. 175-182, 1996.

[7] K. Yoshioka, V. Petrykin, M. Kakihana, H. Kato, and A. Kudo, "The relationship between photocatalytic activity and crystal structure in strontium tantalates," Journal of Catalysis, vol. 232, no. 1, pp. 102-107, 2005.

[8] H. Otsuka, K. Kim, A. Kouzu et al., "Photocatalytic performance of $\mathrm{Ba}_{5} \mathrm{Ta}_{4} \mathrm{O}_{15}$ to decomposition of $\mathrm{H}_{2} \mathrm{O}$ into $\mathrm{H}_{2}$ and $\mathrm{O}_{2}$," Chemistry Letters, vol. 34, no. 6, pp. 822-823, 2005.

[9] T. Kurihara, H. Okutomi, Y. Miseki, H. Kato, and A. Kudo, "Highly efficient water splitting over $\mathrm{K}_{3} \mathrm{Ta}_{3} \mathrm{~B}_{2} \mathrm{O}_{12}$ photocatalyst without loading cocatalyst," Chemistry Letters, vol. 35, no. 3, pp. 274-275, 2006.

[10] S. C. Yan, Z. Q. Wang, Z. S. Li, and Z. G. Zou, "Photocatalytic activities for water splitting of La-doped- $\mathrm{NaTaO}_{3}$ fabricated by microwave synthesis," Solid State Ionics, vol. 180, no. 32-35, pp. 1539-1542, 2009.

[11] Y. Zou, Y. Hu, H. Gu, and Y. Wang, "Optical properties of octahedral $\mathrm{KTaO}_{3}$ nanocrystalline," Materials Chemistry and Physics, vol. 115, no. 1, pp. 151-153, 2009.

[12] T. Ishihara, H. Nishiguchi, K. Fukamachi, and Y. Takita, "Effects of acceptor doping to $\mathrm{KTaO}_{3}$ on photocatalytic decomposition of pure $\mathrm{H}_{2} \mathrm{O}$," Journal of Physical Chemistry B, vol. 103, no. 1, pp. 1-3, 1999.

[13] T. Ishihara, N. S. Baik, N. Ono, H. Nishiguchi, and Y. Takita, "Effects of crystal structure on photolysis of $\mathrm{H}_{2} \mathrm{O}$ on $\mathrm{K}-\mathrm{Ta}$ mixed oxide," Journal of Photochemistry and Photobiology A, vol. 167, no. 2-3, pp. 149-157, 2004.

[14] B. Zielińska, E. Borowiak-Palen, and R. J. Kalenczuk, "Preparation, characterization and photocatalytic activity of metalloaded $\mathrm{NaNbO}_{3}$," Journal of Physics and Chemistry of Solids, vol. 72, no. 2, pp. 117-123, 2011.

[15] R. R. Krishnan, R. Vinodkumar, G. Rajan, K. G. Gopchandran, and V. P. Mahadevan Pillai, "Structural, optical, and morphological properties of laser ablated $\mathrm{ZnO}$ doped $\mathrm{Ta}_{2} \mathrm{O}_{5}$ films," Materials Science and Engineering B, vol. 174, no. 1-3, pp. 150$158,2010$.

[16] D. Jing and L. Guo, "Hydrogen production over Fe-doped tantalum oxide from an aqueous methanol solution under the light irradiation," Journal of Physics and Chemistry of Solids, vol. 68, no. 12, pp. 2363-2369, 2007.

[17] G. K. Liu, V. S. Vikhnin, and S. E. Kapphan, "Light-induced metastable states in ferroelectric oxides," Optical Materials, vol. 29, no. 11, pp. 1394-1399, 2007.

[18] A. Tkach, A. Almeida, J. Agostinho Moreira, M. R. Chaves, A. Espinha, and P. M. Vilarinho, "Polar behaviour induced by lithium in potassium tantalate ceramics," Journal of Physics Condensed Matter, vol. 24, no. 4, Article ID 045906, 2012.

[19] A. K. Chakraborty, Z. Qi, S. Y. Chai et al., "Formation of highly crystallized $\mathrm{TiO}_{2}(\mathrm{~B})$ and its photocatalytic behavior," Applied Catalysis B, vol. 93, no. 3-4, pp. 368-375, 2010. 


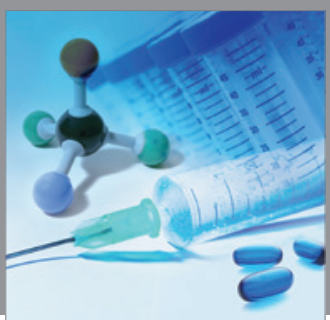

International Journal of

Medicinal Chemistry

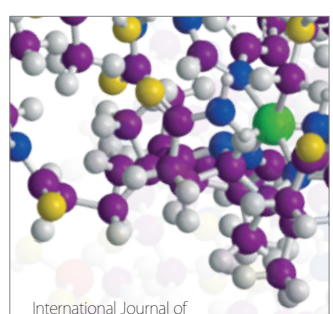

Carbohydrate Chemistry

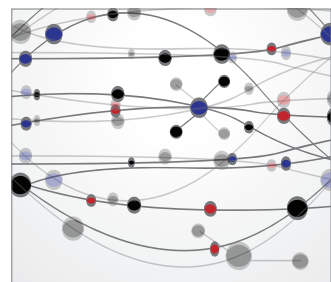

The Scientific World Journal
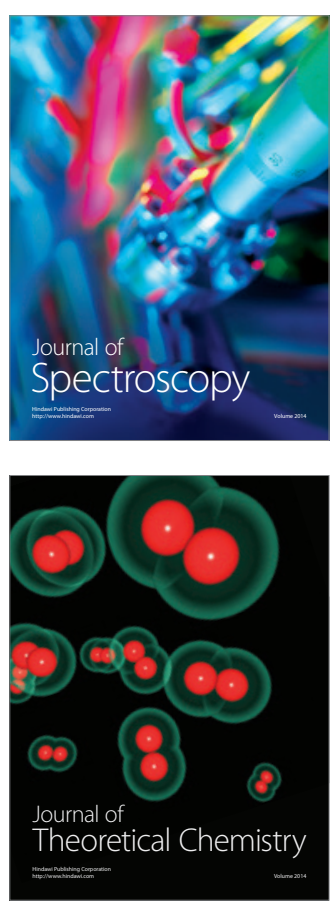
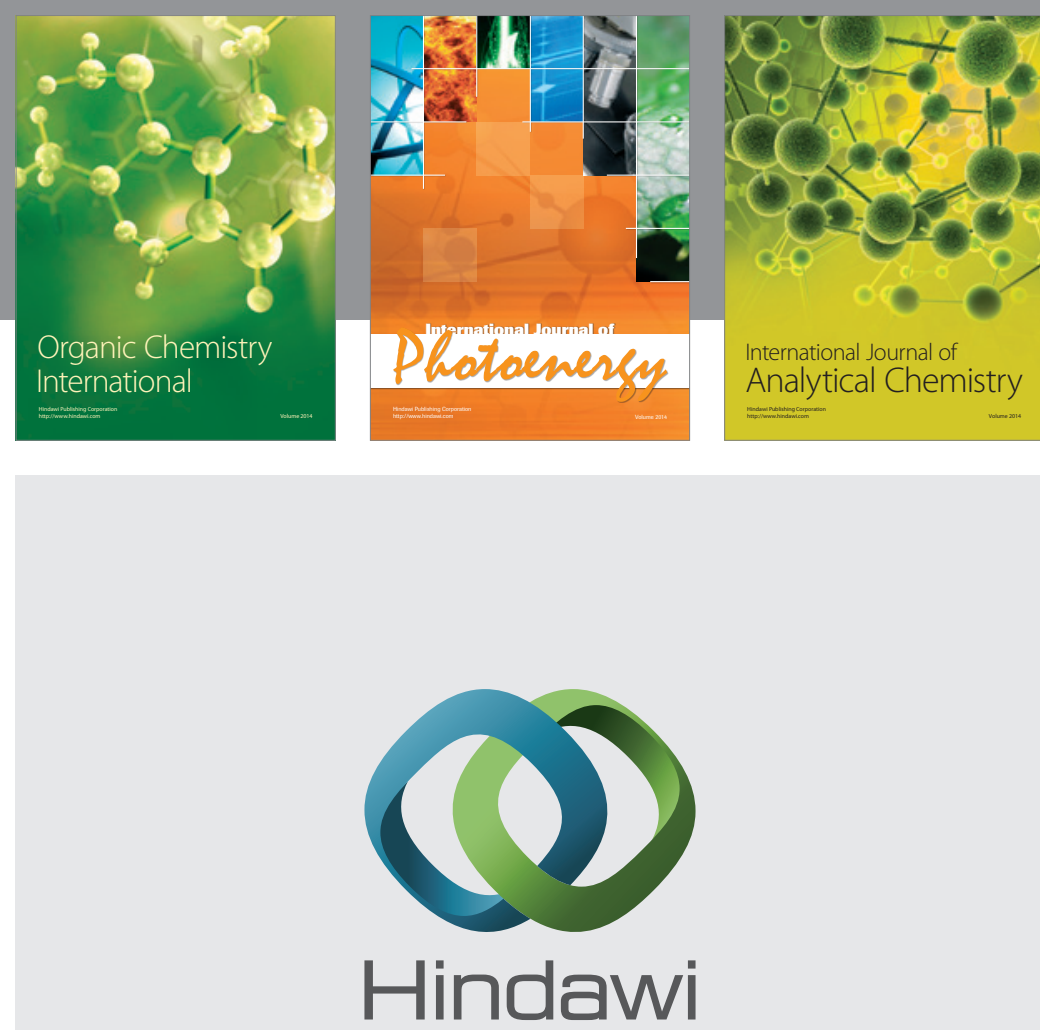

Submit your manuscripts at

http://www.hindawi.com
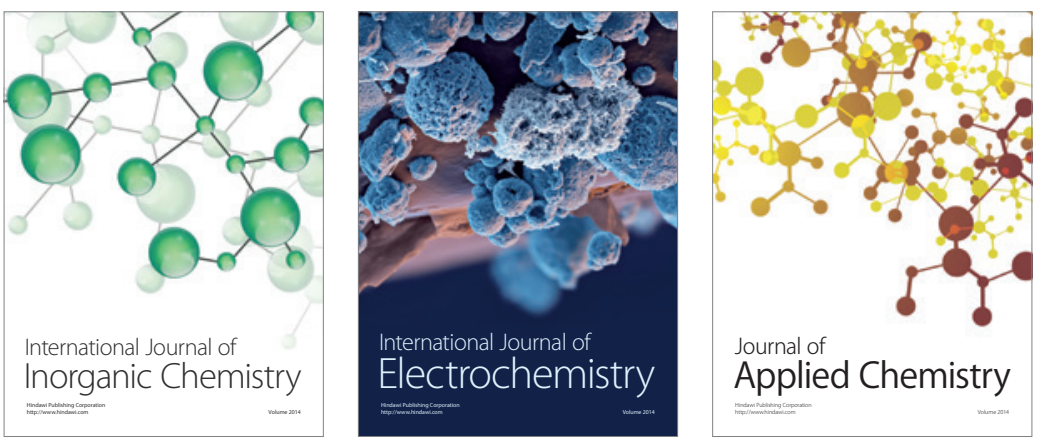

Journal of

Applied Chemistry
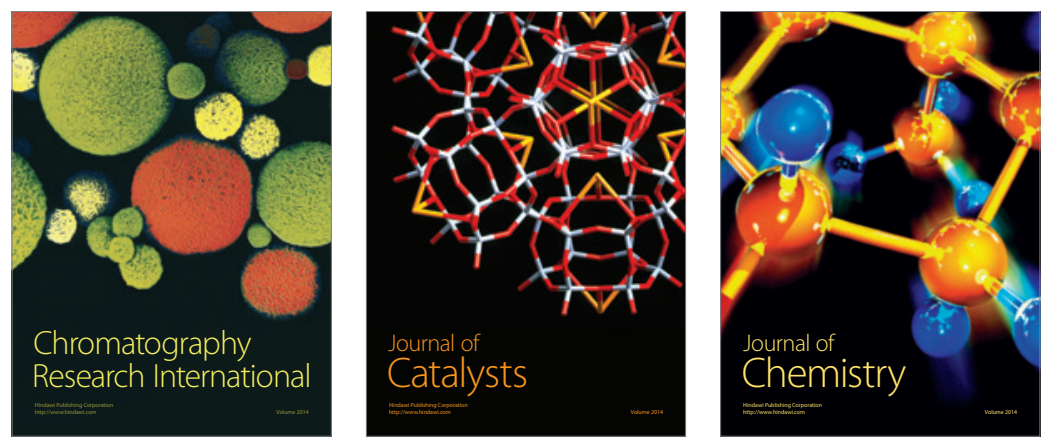
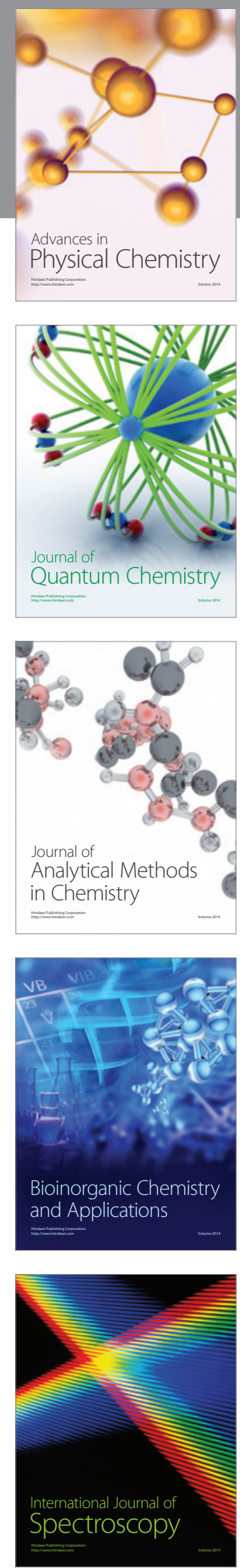